induced hyperkinetic syndrome. Lancet May 9, 1992; 339:1150-1153.) (Correspondence: Dr. J. Egger, Universitatskinderklinik, Lindwurmstrasse 4, 8000 Munchen 2, Germany.)

COMMENT: Dr. Egger also reports a beneficial effect of the hypoallergenic diet in 12 children who suffered from enuresis in association with migraine and the hyperkinetic syndrome (Egger $\mathrm{J}$ et al. Clin Pediatr May 1992; 31:302-307). In an editorial Fitzwater D and Macknin ML (Clin Pediatr 1992; 31:308-310) recommend additional studies before dietary therapy can be introduced as a standard therapy for enuresis. Given the hazards of pharmacological therapy and the practical disadvantages of the alarm system, Dr. Egger's dietary and hyposensitization methods deserve attention. For reviews of previous articles on the hypoallergenic diet, see Progress in Pediatric Neurology, Ed Millichap JG 1991, p. 88-89.

\title{
PRENATAL HEAVY METAL EXPOSURE AND COGNITION
}

The effects of prenatal exposure to heavy metals on childhood cognitive skills and health status are reported from the Robert Wood Johnson Medical School, New Brunswick, NJ. Cadmium, chromium, cobalt, lead, mercury, nickel and silver were determined in amniotic fluid taken from 92 pregnant women at 16 - 18 weeks gestation. A prenatal toxic risk score was based on the presence of a detectable level for the various metals. A correlation analysis indicated a negative relation between the toxic risk score and cognitive performance and a significant positive correlation between the toxic risk score and both the total number of atopic illnesses and infections assessed at 3 years of age. These findings indicate that health status as well as cognitive ability may show deficits as a consequence of prenatal heavy metal exposure. (Lewis $M$ et al. Prenatal exposure to heavy metals: effect on childhood cognitive skills and health status. Pediatrics June 1992; $\underline{89}: 1010$ 1015.) (Reprints: Dr. Michael Lewis, Institute for the Study of Child Development, Dept. of Pediatrics, UMDNJ-Robert Wood Johnson Medical School, RWJ Professional Bldg. New Brunswick, NJ 08903-0019.)

COMMENT. Lead intoxication in infants is common and is of different origin from that in toddlers (Shannon MW, Graef JW. Lead intoxication in infancy. Pediatrics Jan 1992; 89:87-90). Formula preparation with lead contaminated water accounted for 9 of 50 infantile cases whereas paint chip ingestion was the most common cause among 47 children $(86 \%)$ aged 18 through 30 months. These data support recent recommendations to initiate lead screening in children at 6 months of age. A maintained average blood level of $25 \mathrm{ug} / \mathrm{dL}$ or more during the second and third year of life was found to be detrimental to the child's attained stature at 33 months of age in a study from the University of Cincinnati (Shukla $\mathrm{R}$ et al. Lead exposure and growth in the early preschool child: A follow-up report from the Cincinnati lead

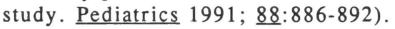

